\title{
Neuroanthropology Olfactory Recognition of the Self / Non-self by the Ancestral MHC: An EEG Study
}

\author{
Emma Marxer-Tobler ${ }^{1} \&$ Jaime Pineda $^{1}$ \\ ${ }^{1}$ Department of Cognitive Neuroscience, University of California, San Diego, CA, USA \\ Correspondence: Emma Marxer-Tobler, Max-Planck-Institute, Advokatenweg 36, Halle (Saale) 06114, Germany. \\ Tel: 49-345-2927-167. E-mail: emma.marxer@freesurf.ch
}

Received: June 29, 2012 Accepted: July 18, 2012 Online Published: August 22, 2012

doi:10.5539/ijb.v4n4p1 URL: http://dx.doi.org/10.5539/ijb.v4n4p1

\begin{abstract}
Humans naturally discriminate between different ethnic group members using visual and other sensory information, including the sense of smell. The genetic diversity of humans serves as biological and social sign stimuli in the neural self/non-self recognition process. As already evident, the major histocompatibility complex (MHC) encodes both an individual self and a shared ancestral self into the body odor. In a pilot study, we examine the brain-evoked responses to ancestral encoded body odors by conducting an olfactory EEG recording of four different groups: Germans, Taiwanese, Koreans, and Chinese. Results show that humans recognize in-group members as familiar and they exhibit practically identical rhythmic EEG patterns to one's own odor as it pertains to the ancestral in-group odors. This reveals their genetic relatedness. It is hereby demonstrated that shared ethnicity results in behaviors (both group-protective and pro-social) that are important to intra- and inter-group dynamics.
\end{abstract}

Keywords: ethnicity, culture, pheromone, neurology, self-reference system, prosocial behavior, body odor, ancestral frozen blocks

\section{Introduction}

Since processes of self/non-self recognition are evolved mechanisms lying at the core of development, immune defense and socio-cultural behavior (Boehm, 2006; Boulanger \& Shatz, 2004a; Villinger \& Waldman, 2008a), it is likely that specific neural mechanisms evolved in order to encode and process them (Insel \& Fernald, 2004). Such self/non-self recognition processes can be classified as conserved neural mechanisms (Paulsen \& Sejnowski, 2006) serving as a survival kit in the competition of the evolutionary process. The immune self/non-self recognition is an innate and adaptive mechanism evolved from ancient times. It evaluates genetic relatedness (Boehm, 2006) and serves not only for chemical but also for social recognition (Porter, 1998; Yamazaki, Beauchamp, Curran, Bard, \& Boyse, 2000; Wedekind, Seebeck, Bettens, \& Paepke, 1995; Santos, Schinemann, Gabardo, \& Bicalho, 2005). In humans, the self/non-self recognition revolves around an ethnic distinction where ethnicity is defined as the identity of a group of human beings whose members identify with each other and share true common ancestry (Barth, 1969). This genetically-inherited information provides clues that are perceived and understood by the neural mechanisms.

One such neural mechanism is the olfactory sensory system, well established in animals, which uses chemical signals encoded in body fluids to convey social information (Yamazaki et al., 2000; Yamazaki \& Beauchamp, 2007a). Olfaction is argued to be a remote sense, which not only protects against poisoned food but also awakens individuals in the case of fire a long distance away. As already widely explored, olfaction additionally has a function in social behavior such as kin recognition (Porter \& Moore, 1981; Porter, Cernoch, \& Balogh, 1985; Porter, 1998), mate choices (Wedekind et al., 1995; Wedekind \& Penn, 2000; Santos et al., 2005; Beauchamp et al., 1995; Yamazaki \& Beauchamp, 2007b; Yamazaki et al., 2000; Wedekind et al., 1995), incest avoidance (Weisfeld, Czilli, Phillips, Gall, \& Lichtman, 2003), pregnancy block (Yamazaki et al., 1983), lactose, and mother preferences in babies as young as three days old (Jacob et al., 2004), and in synchronizing women's menstruation cycles by triggering and controlling biological effects (Jacob, McClintock, Zelano, \& Ober, 2002; McClintock et al., 2005). Furthermore, as known in medicine, the olfactory sense plays a role in neurogenesis 
(Graziadei \& Monti Graziadei, 1985), and in diseases leading to dementia (Murphy, 1999). In humans, for a long time the olfactory sense has been believed to be negligible in favor of vision, but in the last two decades, this viewpoint has been altered by many studies.

The last two decade, studies have confirmed that the individual body odor in most vertebrates, including humans, is associated with their allelic profile of the major histocompatibility complex (MHC) (Ehlers et al., 2000; Ziegler, Santos, Kellermann, \& Uchanska-Ziegler, 2010; Yamazaki et al., 2000; Boehm \& Zufall, 2006; Eggert et al., 1998a). The MHC class I and II [in humans called Human Leukocyte Antigen (HLA)] forms a large genomic region or gene family on chromosome 6 , and plays a key role in the social and immunological recognition process (Boehm \& Zufall, 2006; Boehm \& Zufall, 2006; Ehlers et al., 2000; Yamazaki et al., 2000; Wedekind \& Penn, 2000; Boulanger, 2004). The MHC-complex is investigated intensively because of its importance to the immune representation, and immune responses in the disease defence. This genetic structure constitutes therefore, the main factor in determining immunological identity (Eggert et al., 1998b). The MHC-encoded body odor distinguishes not only individuals from one another as a function of its encoded MHC-polymorphism, but also distinguishes ethnic groups (Li et al., 2008; Rushton, Russell, \& Wells, 1984; Traherne et al., 2006; Blomhoff et al., 2006). Then ethnical in-group members share genetic MHC-loci, so called frozen blocks (PFBs) at the regions from HLA-DR to HLA-DQ (Gaudieri, Leelayuwat, Tay, Townend, \& Dawkins, 1997; Blomhoff et al., 2006). Ethno-specific haplotypes contain conserved genomic sequences that are shuffled by recombination inhibition (Gaudieri et al., 1997). Conclusively, we infer that genetically encoded odor gives each individual both a specific identity (self) composed by the MHC-polymorphic (recombined) genes unique to that person, and a group-shared set of alleles conserved and less transformed on the MHC-complex, class II, DR-DQ (1999).

For personal protection, this highly-polymorphic group of MHC-genes integrates peptide ligands (Singh, 2001) into the membrane of each body cell, including neural and skin cells (Boulanger \& Shatz, 2004b). MHC-protein ligands also tag, or saturate one's own body fluids with these genetic markers (Ehlers et al., 2000; Spehr et al., 2006), which give an unmistakable identity to each individual recognized through olfaction. As each individual secretes these genetically-inherited protein ligands into their environment, it is easy to conceive that individuals are ubiquitously surrounded by genetically-encoded information from others. Once released, this information is received, understood and interpreted by the olfactory neural recognition mechanisms, powerful enough to influence others' endocrine systems without their awareness (Strous \& Shoenfeld, 2006b). To identify genetic relatedness via olfaction is of vital importance because the immune self/non-self mechanism furnishes recognition through this pathway, not only for autoimmunity in terms of the brain's endocrine responses (Strous \& Shoenfeld, 2006a), but also given that the olfactory system translates olfactory clues into neuro-endocrine signals (Kohl, Atzmueller, Fink, \& Grammer, 2001). The key property of being identified recognized and categorized into a self or a non-self lies at the core of both the immune system and human social systems.

To quantify ethnic inheritance, we conducted an EEG recording. We hypothesized that when ethnic heredity arises as a function of the immune self/non-self distinction not only encoding the personal body odor but also providing the recognition mechanisms (Yamazaki et al., 1983; Schaefer, Yamazaki, Osada, Restrepo, \& Beauchamp, 2002; Schaefer et al., 2002), we are able to measure this function by exploring neural rhythmic patterns perceived by smelling self-odors, ethnic in-group odors, and ethnic out-group odors. Rhythmic patterns of neuronal activity have been found in animals and humans at multiple levels of various sensory systems including olfaction. Thus, we anticipated that the neural olfactory system would be able to recognize the similarity between the genetically-transmitted individual encoded self and the conserved ethno-genetic self by contrasting these to the ethno-genetic out-group non-self. Furthermore, it would follow that the ethnic heredity would be expressed in neural activity patterns therefore, measurable by electrophysiology. By continuing this idea, we expected similar behavior changes in brain-power, to self-odors and in-group odors, and dissimilar changes to out-group odors.

Olfactory EEG rhythms have been described in delta, theta, alpha, and beta band oscillations. Through many twin studies, it has been established that EEG-parameters are inherited. The heritability (genetic variance) is expressed and measurable in neuronal activities and neural oscillation patterns of the brain (Van Beijsterveldt, Molenaar, de Geus, \& Boomsma, 1996). Some EEG studies done on twins showed that the neural response patterns of an individual are almost stable across their entire life time (Van Beijsterveldt et al., 1996). Additionally, that heritability for the alpha frequency is $89 \%$, the highest when compared with a delta frequency of $76 \%$, and a beta frequency of $86 \%$. In her study, it was also shown that there were genetic similarities and dissimilarities that had to be expressed and rendered visible in the rhythmic activity patterns (Van Beijsterveldt et al., 1996). 


\section{Materials and Methods}

\subsection{Participants}

We tested in a preliminary study four ethnic groups: Chinese, Taiwanese, Koreans, and Germans. Twelve healthy females (three of each ethnic group who were visiting students at the University of California, San Diego) participated in the experiment. Nine were undergraduate students (age range: 19-23 yrs: mean, 20 yrs) participating for credit, and three that were postdoctoral participants (age range: $24-30$ yrs: mean, 27 yrs) participating for compensation. In a personal briefing, we queried the ethnic ancestry of the participants. They were eligible to participate in the experiment only when they could demonstrate three generations from the same ethnic group as well as from the same geographical area. Bio-medical statements have determined that self-reported ancestry is sufficient to account for the inherited ethno-genetic similarities, except for societies involving recent ethnic admixture ( $\mathrm{Li}$ et al., 2008). These statements allowed us to establish the ethno-genetic affiliation of our subjects via personal interviews. Additionally we took only women because we did not want to confound the ethno-genetic perception with odor-triggered gender preferences. All participants participated in two sessions for which they gave their written consent. The protocol was approved by the Institutional Review Board at the University of California, San Diego.

\subsection{Collecting Olfactory Stimuli}

Participants were asked to wear a plain white T-shirt for four consecutive nights while they slept. The T-shirts were all from the same stock and pre-washed with the same unscented detergent. They were given to participants in a closed plastic bag, as was the shower soap (Dove, unscented). Additionally, a list of 21 foods and spices to avoid, such as garlic, cardamom, and asparagus, were provided together with behavior instructions. The instructions advised participants to use only the given soap, and not any additional fragrance, perfumes, deodorants, or lotions during the four days. All participants were non-smokers and were not pet owners. They were asked that, if exposed to cigarette smoke or other strong environmental odors, they were to shower with the soap provided before putting on the T-shirt. They were also asked to refrain from drinking alcohol, and engaging in sexual activities, while, or to shower before wearing the T-shirt. In the morning, participants were required to put the T-shirt into the supplied plastic bag. At the end of the four days, the plastic bags with the T-shirts were placed in a freezer.

\subsection{Experimental Design}

Seven odors [non-odor, in-group odors, out-group odors (German, Korean, Taiwanese, and Chinese)] in the form of different T-shirts were randomly presented (double blind) to each participant. Five participants were also exposed to the self-odor. A non-odor in the form of an unused T-shirt (prewashed as were the other T-shirts) was used as a baseline control odor. Participants were asked to smell/sniff each T-shirt for approximately 2 minutes by putting the T-shirt near their nose. Two minutes were recorded in order to obtain enough clean EEG data for analysis. Before each presentation, the T-shirts were warmed up in a microwave for 10 seconds. Following each trial of presenting an odor, there was a rest period of approximately 4 mins while participants rated the stimulus as either familiar or unfamiliar, and ranked the odor using a Likert scale (1-5) as either very pleasant, pleasant, neutral, unpleasant or very unpleasant. At the end of all seven trials participants had to score the most pleasant and most unpleasant odor.

\subsection{EEG Recording}

EEG data was collected in an electromagnetically and acoustically-shielded darkened chamber, with the subject sitting in a comfortable chair. The EEG data was recorded from six electrode sites embedded in a cap at the following scalp positions: FP2, Fz, Cz, Pz, C3, C4, according to the International 10-20 System. Following placement of the cap, electrolytic gel was applied at each electrode site and the skin surface was lightly abraded to reduce the impedance of the electrode-skin contact. The impedance on all electrodes was measured and confirmed to be less than $10 \mathrm{KOhms}$ both before and after testing. EEG data was also recorded from linked MST (mastoid) sites behind each ear. The computationally linked mastoids were used as reference electrodes. The EEG was recorded and analyzed using a Neuroscan Synamps system (bandpass 0.1-30 Hz). Data was collected at a sampling rate of $500 \mathrm{~Hz}$.

\subsection{EEG Data Analysis}

For our data analysis, eye blinks, and eye and head movements were manually identified in the recording, along with other EEG artifacts removed prior to analysis according to standard criteria. Data was only analyzed if there were sufficient "clean" samples with no movement or eye blink artifacts. For the spectral analysis, each cleaned data set was segmented into an epoch of $60000 \mathrm{~ms}$ with a bandpass of $1-30 \mathrm{~Hz}$, with each beginning at the start of 
the segment. Changes in EEG power in the 8-13 Hz frequency band was subjected to a log transformation prior to the statistical analysis by forming a ratio of the power during the experimental condition relative to the power in the unused condition of the baseline T-shirt. A ratio was used to control variability in absolute power-band as a result of individual differences such as scalp thickness, electrode impedance, and breathing, as opposed to differences in neuron activity.

Since the spectral analysis converts the EEG from the time domain to a frequency domain and decomposes them into pure sine waves of different frequencies, it estimates the spectral densities at different frequencies (Rushton et al., 1984). The outcome is a power spectrum in the band showing the frequencies at the horizontal axis and the squared voltage at the vertical axis (Figure 1). All EEG data of the subjects was taken $(n=12 \times 7 \times 6=504)$ to find the most computed frequency of the olfactory signals in the absolute power spectrum.

A cross-coherence (cross-spectral) analysis was made to render visible the variation of the frequencies in the different power bands. The cross-coherence measures the degree of relatedness between electrodes or between signals by shifting the waveform from the time domain into the frequency domain and then computing the correlation. Based on the data of the spectral analysis, we compared the three data sets (self $\mathrm{x}$ in-group $\mathrm{x}$ out-group) ( $\mathrm{n}=5 \times 10 \times 5=250)$. If the variability in the processing of self, in-group, and out-group odor is interrelated in the higher spectral domain, the cross-coherence identifies these differences. We predicted that the variation in a given frequency between self and in-group odors would be smaller than the variation between self and out-group odors (Figure 2).

\subsection{Statistical Analysis}

In order to test whether there is a linear dependence comparing self-odors with in-group odors or comparing self-odors with out-group odors, a bivariate Pearson correlation was made for all electrodes: (self $\mathrm{x}$ in-group; and self $x$ out-group). As a Pearson correlation measures the strength of the linear dependence between two variables, we expected a high correlation for self and in-group odors, and a low correlation for self and out-group odors. The Pearson correlation was computed with the data of the spectral analysis.

To determine means calculating the deviation from the null-hypothesis, we did a paired sample t-test to self versus in-group odors, self versus out-group odors, and in-group versus out-group odors. As the t-test is a two-sample test measuring the specific means of a normally distributed population, it is assumed to be normally distributed when the sample size is small enough that the statistical inference is based on the uncertain estimate. We expected from the t-test that the means of deviation of self and in-group would yield similar values so that the $\mathrm{p}$-value would be larger than 0.05 ; whereas, the means of self and out-group would yield dissimilar values so that the p-value would be smaller than 0.05 . It is also anticipated that the means of in-group and out-group would yield dissimilar values so that the $\mathrm{p}$-value would also be smaller than 0.05 .

\section{Results}

\subsection{Rating Performance}

Seventy five percent (75\%) of participants (nine out of twelve) scored in-group odors as familiar suggesting that participants subjectively recognized in-group odors as familiar. However, in terms of pleasantness scoring, the subjective recognition test of the participants regarding pleasant/unpleasant rating yielded no significant pattern. Although in the rating of most pleasant and most unpleasant following the experiment, $66 \%$ of the participants ( 8 out of 12) rated the unused T-shirt as most pleasant, whereas $66 \%$ (8 out of 12) of the participants recognized an out-group odor as the source of the most unpleasant odor.

\subsection{Electrophysiology (EEG)}

The following spectral analysis reveals a remarkable amount of increased delta $(1-4 \mathrm{~Hz})$ waves that reflect the lowest frequencies and the highest amplitudes (Figure 1). 


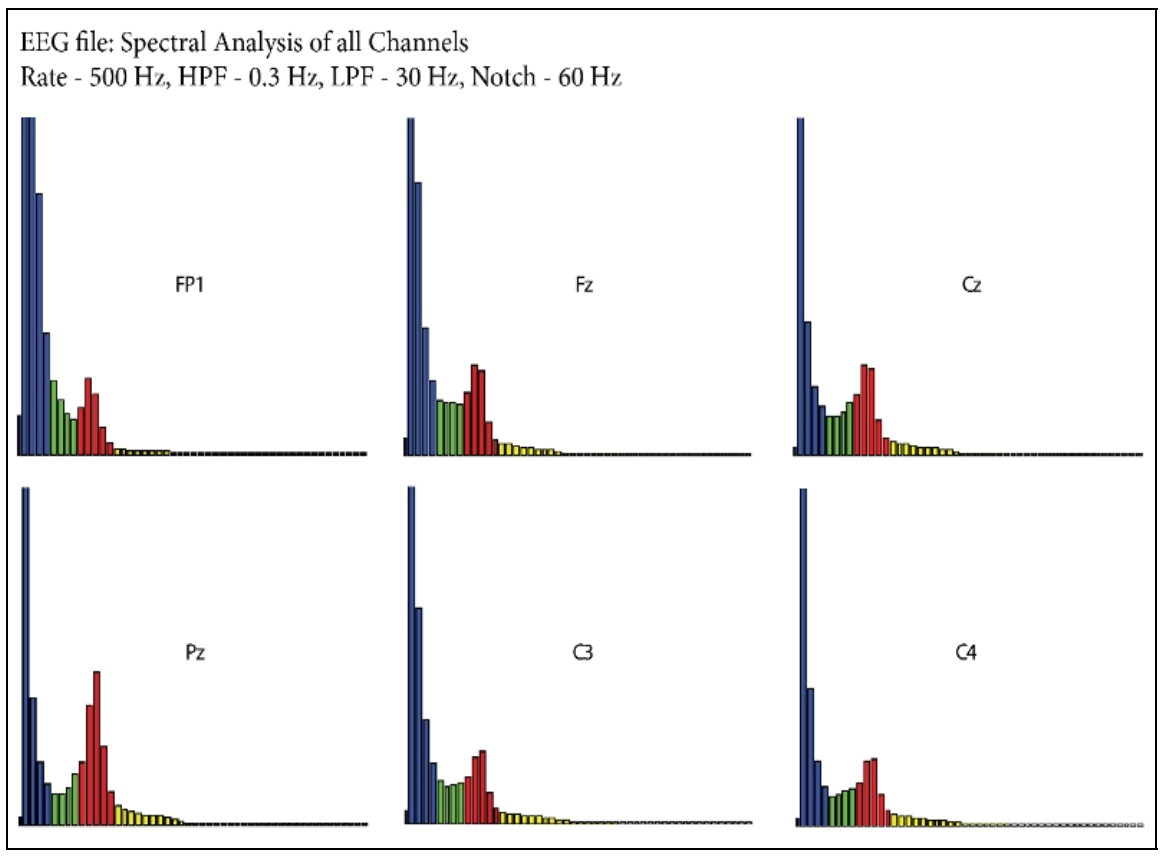

Figure 1. The spectral analysis shows amplitude differences in the frequency bands. There is much neural activity in the low frequency bands, but also in the alpha frequency band

Although low waves in general are not the subject of the EEG analysis except in sub-cortical lesions and sleep, it is generally known that delta waves are dominant in children up to one year and in adults in sleep stages. Recent investigations show that there are increased delta waves in states of contemplation (www.noetic.org/research/ medbiblio/ch1.htm). Humans obviously increase delta waves in order to decrease their awareness of the outside world. Therefore, in general, delta waves may reflect an unconscious process. Since our study supports the fact that the MHC guided recognition-processes are processes not conscious but unconscious, this needs further investigation. However, for our study, the most interesting computation is performed in the $8-13 \mathrm{~Hz}$ band.

The cross-coherence analysis makes visible (Figure 2) that, at first there are bursts of neural activity on the $11 \mathrm{~Hz}$ frequency to self and in-group responses at all electrodes. Furthermore, it identifies its converging power at the low beta band between $13 \mathrm{~Hz}$ and $22 \mathrm{~Hz}$ computing self-odor and in-group odor, but diverges within these frequencies when computing out-group odors. Therefore, within an ethnic group, across all explored groups, the neural responsiveness showed remarkable similar response pattern. This result supports the idea that the neural system recognizes the ethno-genetic self-identity and discriminates it from the out-group non-self-identity.

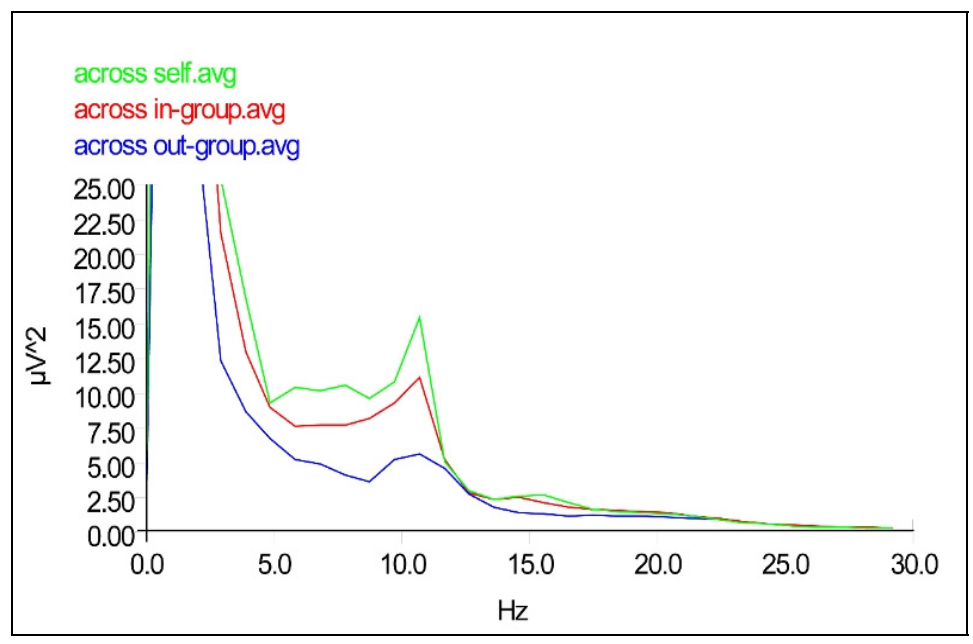

Figure 2. The graph shows the power spectrum between self (green), in-group (blue) and out-group (red) 
In concrete numbers, Figure 3 demonstrates that on all electrode sites the differences between self and in-group is lower than self and out-group. Especially on the electrode side C3, there are practically no differences in odor processing between self and ethnic in-group but statistically significant differences compared to ethnic out-group.

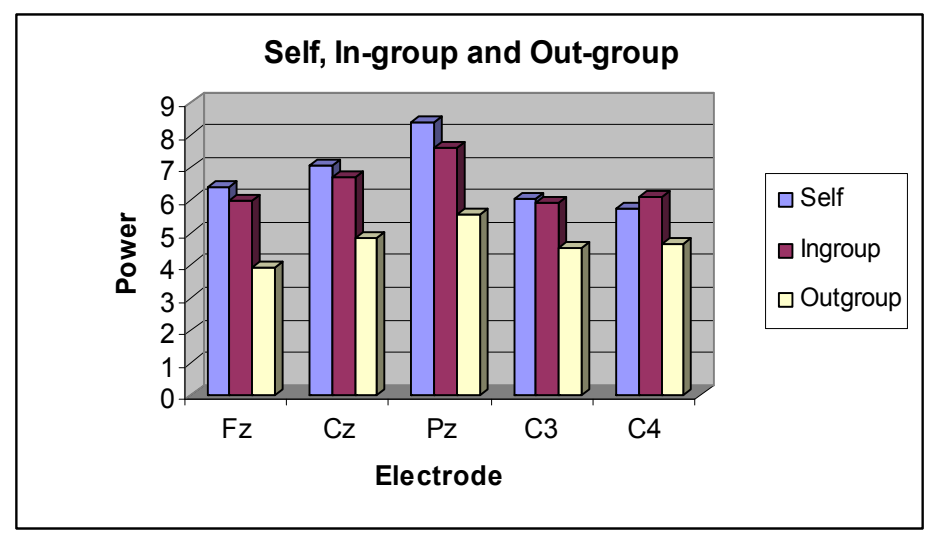

Figure 3. Absolute power spectrum of the self-odor, in-group odor, and out-group odor on the electrode sites of $\mathrm{Fz}, \mathrm{Cz}, \mathrm{Pz}, \mathrm{C} 3, \mathrm{C} 4$

Based on the absolute spectral power, our most striking results were found in comparing the self-odor with the in-group odors. As visible in Figure 2, and 3, the participants responded to self-odor as to any in-group odor in similar frequency patterns, on all electrode sites. These results speak clearly to the neural perception and recognition of the ethno-genetic self, bodily encoded by the immune MHC-complex.

\subsubsection{Results of the Bivariate Pearson Correlation}

The bivariate Pearson correlation measuring the relationship between the two variables of self and in-group was statistically significant. The correlation coefficient ratified that self and in-group responses were highly linear when correlated with each other's (self - in-group: $r=0.973 ; p=0.005$, whereas self and out-group responses were low correlated (self - out-group: $\mathrm{r}=0.473, \mathrm{p}=0.421$ ). The result speaks to the perception of the ethno-genetic relatedness within an ethnic group.

\subsubsection{The Results of the T-Test}

The independent t-test assesses whether the means of two groups are statistically different from each other. As a t-test is an optimal measurement in small samples, we tested whether the means of the self-odor differed from the means of the in-group odors. The means of the self differed from the means of the out-group odors, and the means of the in-group odors differed from the means of the out-group odors. As expected, the paired sample $\mathrm{t}$-test ratified that self $(\mathrm{M}=6.73, \mathrm{SD}=1.06)$ is not significantly different to in-group $(\mathrm{M}=6.47, \mathrm{SD}=0.72), \mathrm{t}(5)=1.41$, $\mathrm{p}=0.231$. Whereas the paired sample $\mathrm{t}$-test to self versus out-group revealed that self $(\mathrm{M}=6.73, \mathrm{SD}=1.06)$ is significantly different to out-group $(\mathrm{M}=4.69, \mathrm{SD}=0.58), \mathrm{t}(5)=6.32 ; \mathrm{p}=0.003$. Additionally, comparing in-group to out-group, the paired sample t-test ratified that in-group $(\mathrm{M}=6.47, \mathrm{SD}=0.72)$ was also significantly different to out-group $(\mathrm{M}=4.69, \mathrm{SD}=0.58), \mathrm{t}(5)=11.92 ; \mathrm{p}=0.000$. This result confirms our assumption.

\subsubsection{Repeated Stimuli}

Ten of the participants were exposed to more than one odor from various ethnic groups, and four participants to more than one odor in the in-group allowing comparison of repeated presentations of the stimuli. Half of the participants, $50 \%$ (five out of ten) experiencing multiple out-group odors showed greater suppression to the second presentation of the odor, while $75 \%$ (three out of four) of those experiencing multiple in-group odors showed more suppression to the second one, suggesting increased sensitivity to in-group odors.

\section{Discussion}

The present pilot study is the first time that behavioral and electrophysiological changes have supported the idea that ethno-genetic self-identity, encoded by the conserved ancestral MHC-genes may be measurable by the neural activity in response to olfactory stimuli. Distinct body odors of four different ethnic groups (German, Taiwanese, Korean, and Chinese) were recorded and analyzed in twelve participants using the rhythmic 
oscillations in the EEG spectral band and in the 8-13 Hz band. Additionally, these participants scored the familiarity and pleasantness of the odors using a 2-point and a 5-point Likert scale. By recording behavioral preferences as well as EEG activity in response to self-odor, ethnic in-group odor, and ethnic out-group odor, we have shown that an individual's neural system not only recognizes ethnicity by discriminating in-group versus out-group but also that participants' electrophysiological brain-responses showed remarkable similarity within an ethnic in-group. This observation supports the idea that a genetic relatedness exists between self and in-group odors. Furthermore, besides a similar responsiveness to in-group odors, there is highly individualized sensitivity to out-group odors.

The rating evaluation also showed some surprising trends. First, participants judged the ethnic in-group odors as familiar but did not respond similarly to their own odor. This seems to serve as an analogy to the existence of the visual blind spot. Second, in terms of pleasantness and unpleasantness ratings, there were no significant patterns. Third, when asked to judge the most pleasant/unpleasant odor, participants rated the control T-shirt as the most pleasant odor. For the most unpleasant odor, they generally picked an ethnic-out-group odor. We infer from these behavior results that first participants were able to recognize their own ethnic affiliation by familiarity but not by pleasantness. These results support the hypothesis that ethno-genetic self-recognition triggered by olfactory cues produces feelings of familiarity and therefore, of security and trust. Finally, the subjective rating evaluations revealed further that subject were not able to recognize consciously their own odor. That result indicates an unconscious process, which may be expressed in the many low wave EEG activities we found. However, this remains to be explored.

Also the electrophysiological results showed that individuals at the neural level are able to discriminate in-group members from ethnic out-group members, without being consciously aware of it. Additionally, the electrophysiological responses are highly individualized, as visible in the response patterns of each subject. Therefore, it argues that each person has an individualized body odor composed of both their individualized genetic polymorphism, and of their ethnically-shared genes on the same structure. This result is consistent with the idea that MHC-based identification, at the level of cells, provides an identity at the level of the individual that is discernable via olfaction. It thus supports the hypothesis that this MHC-encoded odor-identity serves as an ethno-genetic marker (ethnic encoded fingerprint) in a self/self (autoimmune), and self/non-self recognition process, which is already evident at the level of the immune system.

Our key and most exciting electrophysiological findings demonstrated that similar neuronal response-patterns within an ethnic group indicate their genetic relatedness. Therefore, we can safely interpret that the brain, at the level of the EEG, recognizes the ethnically-shared alleles in olfactory cues as a genetic self-identity. Consider Villinger's et al. (2008) self-referent matching evidence in tadpoles. This shows that tadpoles use the MHC-matching loci to socially discriminate among conspecifics by using their odor self-referent matching of MHC-determined genotypes (Villinger \& Waldman, 2008b). Accordingly, our results indicated that humans are also capable of using their ethno-genetically shared self-identity to identify ethnic non-self identities. It suggests that also humans are able to use their ethnically-conserved alleles as a self-reference matching system to recognize their ethnic in-group members, in order to categorize and organize their own socio-cultural worlds.

The results of the repeated stimuli showed that in overall, there was more suppression to the second presented stimuli. Therefore, we can interpret that no habituation took place in the genetic self/non-self recognition process. That implies that on a neural level no memory consolidation is involved. This idea is also consistent with Wang's et al. (2004) study, which showed that with repetitive exposure to androstenone, people could increase their sensitivity but not their habituation to the odor (Wang, Chen, \& Jacob, 2004). Furthermore, as subjects answered stronger to the second stimuli when sensing in-group odors, we can interpreted that the in-group odors may provide information more meaningful because this may provide an individual with tools for prosocial in-group behavior.

In summary, our present study suggests that self-identity arises from an ethnically-inherited MHC-based-self recognized by the neural system. The brain may use the ancestral inherited self-identity as a self-reference mechanism, which then decodes the information, makes a judgment, and differentiates self from non-self. These ethnically inherited protein-ligands are secreted by each individual, added to one's own body odor, and serve as an important identity-marker in the recognition process. Since the odor-information received by olfactory receptor cells triggers the endocrine response by bypassing the thalamus and other cortical areas, it makes available affect-laden social responses. One such response is performing altruistic or hedonic behaviors (Rushton et al., 1984), another is a defense reaction such as ethnocentrism and xenophobia. Then these endocrine triggered behaviors favor evolutionarily the in-group over the out-group. Furthermore, the ethnically-shared and genetically-related MHC-identity may also have a function to bind members of an ethnic in-group to an adapted 
and shared behavior. We can further infer that ethnic bias or prejudice serves as a neuro-social defence mechanism, which is automatically triggered for the protection of one's own ethnic in-group.

\section{Acknowledgements}

I am grateful to Dr. Jaime Pineda for the access to EEG facilities of his lab, for his teaching of how to run the different programs needed for the experiment, also for correcting the language. Additionally, I thank all the readers of the draft of the manuscript, and my brother for his private financial support, without whose help this study could not have been completed. Results were presented in a speech at the Society for Neuroscience (SfN) Conference in Washington, USA, November, 15-19, 2008.

\section{Rerfereces}

Barth, F. (1969). Ethnic Groups and Boundaries. The social organization of culture difference. Oslo: Universitetsforlaget.

Beauchamp, G. K., Katahira, K., Yamazaki, K., Mennella, J. A., Bard, J., \& Boyse, E. A. (1995). Evidence suggesting that the odortypes of pregnant women are a compound of maternal and fetal odortypes. Proc. Natl. Acad. Sci. USA, 92, 2617-2621. http://dx.doi.org/10.1073/pnas.92.7.2617

Blomhoff, A., Olsson, M., Johansson, S., Akselsen, H. E., Pociot, F., Nerup, J., et al. (2006). Linkage disequilibrium and haplotype blocks in the MHC vary in an HLA haplotype specific manner assessed mainly by DRB $1 * 03$ and DRB1*04 haplotypes. Genes Immun., 7, 130-140. http://dx.doi.org/10.1038/sj.gene.6364272

Boehm, T. (2006). Co-evolution of a primordial peptide-presentation system and cellular immunity. Nat. Rev. Immunol., 6, 79-84. http://dx.doi.org/10.1038/nri1749

Boehm, T., \& Zufall, F. (2006). MHC peptides and the sensory evaluation of genotype. Trends Neurosci., 29 , 100-107. http://dx.doi.org/10.1016/j.tins.2005.11.006

Boulanger, L. M. (2004). MHC class I in activity-dependent structural and functional plasticity. Neuron Glia Biol., 1, 283-289. http://dx.doi.org/10.1017/S1740925X05000128

Boulanger, L. M., \& Shatz, C. J. (2004a). Immune signalling in neural development, synaptic plasticity and disease. Nat. Rev. Neurosci., 5, 521-531. http://dx.doi.org/10.1038/nrn1428

Complete sequence and gene map of a human major histocompatibility complex. (1999). The MHC sequencing consortium. Nature, 401, 921-923.

Eggert, F., Luszyk, D., Haberkorn, K., Wobst, B., Vostrowsky, O., Westphal, E., et al. (1998a). The major histocompatibility complex and the chemosensory signalling of individuality in humans. Genetica, 104, 265-273.

Ehlers, A., Beck, S., Forbes, S. A., Trowsdale, J., Volz, A., Younger, R., et al. (2000). MHC-linked olfactory receptor loci exhibit polymorphism and contribute to extended HLA/OR-haplotypes. Genome Res., 10, 1968-1978. http://dx.doi.org/10.1101/gr.10.12.1968

Gaudieri, S., Leelayuwat, C., Tay, G. K., Townend, D. C., \& Dawkins, R. L. (1997). The major histocompatability complex (MHC) contains conserved polymorphic genomic sequences that are shuffled by recombination to form ethnic-specific haplotypes. J. Mol. Evol., 45, 17-23. http://dx.doi.org/10.1007/PL00006194

Graziadei, P. P., \& Monti Graziadei, G. A. (1985). Neurogenesis and plasticity of the olfactory sensory neurons. Ann. N. Y. Acad. Sci., 457, 127-142. http://dx.doi.org/10.1111/j.1749-6632.1985.tb20802.x

Insel, T. R., \& Fernald, R. D. (2004). How the brain processes social information: searching for the social brain. Annu. Rev. Neurosci., 27, 697-722. http://dx.doi.org/10.1146/annurev.neuro.27.070203.144148

Jacob, S., Mc Clintock, M. K., Zelano, B., \& Ober, C. (2002). Paternally inherited HLA alleles are associated with women's choice of male odor. Nat. Genet., 30, 175-179. http://dx.doi.org/10.1038/ng830

Jacob, S., Spencer, N. A., Bullivant, S. B., Sellergren, S. A., Mennella, J. A., \& McClintock, M. K. (2004). Effects of breastfeeding chemosignals on the human menstrual cycle. Hum. Reprod., 19, 422-429. http://dx.doi.org/10.1093/humrep/deh057

Kohl, J. V., Atzmueller, M., Fink, B., \& Grammer, K. (2001). Human pheromones: integrating neuroendocrinology and ethology. Neuro. Endocrinol. Lett., 22, 309-321.

Li, J. Z., Absher, D. M., Tang, H., Southwick, A. M., Casto, A. M., Ramachandran, S., et al. (2008). Worldwide 
human relationships inferred from genome-wide patterns of variation. Science, 319, 1100-1104. http://dx.doi.org/10.1126/science.1153717

Mc Clintock, M. K., Bullivant, S., Jacob, S., Spencer, N., Zelano, B., \& Ober, C. (2005). Human body scents: conscious perceptions and biological effects. Chem. Senses, 30 Suppl 1, i135-i137. http://dx.doi.org/10.1093/chemse/bjh151

Murphy, C. (1999). Loss of olfactory function in dementing disease. Physiol Behav, 66, 177-182. http://dx.doi.org/10.1016/S0031-9384(98)00262-5

Paulsen, O., \& Sejnowski, T. J. (2006). From invertebrate olfaction to human cognition: emerging computational functions of synchronized oscillatory activity. J. Neurosci., 26, 1661-1662. http://dx.doi.org/10.1523/JNEUROSCI.3737-05a.2006

Porter, R. H. (1998). Olfaction and human kin recognition. Genetica, 104, 259-263.

Porter, R. H., \& Moore, J. D. (1981). Human kin recognition by olfactory cues. Physiol Behav, 27, 493-495. http://dx.doi.org/10.1016/0031-9384(81)90337-1

Porter, R. H., Cernoch, J. M., \& Balogh, R. D. (1985). Odor signatures and kin recognition. Physiol Behav., 34, 445-448. http://dx.doi.org/10.1016/0031-9384(85)90210-0

Rushton, J. P., Russell, R. J., \& Wells, P. A. (1984). Genetic similarity theory: beyond kin selection. Behav. Genet., 14, 179-193. http://dx.doi.org/10.1007/BF01065540

Santos, P. S., Schinemann, J. A., Gabardo, J., \& Bicalho, M. G. (2005). New evidence that the MHC influences odor perception in humans: a study with 58 Southern Brazilian students. Horm. Behav., 47, 384-388. http://dx.doi.org/10.1016/j.humimm.2004.07.205

Schaefer, M. L., Yamazaki, K., Osada, K., Restrepo, D., \& Beauchamp, G. K. (2002). Olfactory fingerprints for major histocompatibility complex-determined body odors II: relationship among odor maps, genetics, odor composition, and behavior. J. Neurosci., 22, 9513-9521.

Singh, P. B. (2001). Chemosensation and genetic individuality. Reproduction., 121, 529-539. http://dx.doi.org/10.1530/reprod/121.4.529

Spehr, M., Kelliher, K. R., Li, X. H., Boehm, T., Leinders-Zufall, T., \& Zufall, F. (2006). Essential role of the main olfactory system in social recognition of major histocompatibility complex peptide ligands. $J$. Neurosci., 26, 1961-1970. http://dx.doi.org/10.1523/JNEUROSCI.4939-05.2006

Strous, R. D., \& Shoenfeld, Y. (2006a). Schizophrenia, autoimmunity and immune system dysregulation: a comprehensive model updated and revisited. J. Autoimmun., 27, 71-80. http://dx.doi.org/10.1016/j.jaut.2006.07.006

Strous, R. D., \& Shoenfeld, Y. (2006b). To smell the immune system: olfaction, autoimmunity and brain involvement. Autoimmun. Rev., 6, 54-60. http://dx.doi.org/10.1016/j.autrev.2006.07.002

Traherne, J. A. (2008). Human MHC architecture and evolution: implications for disease association studies. Int. J. Immunogenet., 35, 179-192. http://dx.doi.org/10.1111/j.1744-313X.2008.00765.x

Traherne, J. A., Horton, R., Roberts, A. N., Miretti, M. M., Hurles, M. E., Stewart, C. A., et al. (2006). Genetic analysis of completely sequenced disease-associated MHC haplotypes identifies shuffling of segments in recent human history. PLoS. Genet., 2, e9. http://dx.doi.org/10.1371/journal.pgen.0020009

Van Beijsterveldt, C. E., Molenaar, P. C., de Geus, E. J., \& Boomsma, D. I. (1996). Heritability of human brain functioning as assessed by electroencephalography. Am. J. Hum. Genet., 58, 562-573.

Villinger, J., \& Waldman, B. (2008a). Self-referent MHC type matching in frog tadpoles. Proc. Biol. Sci., 275, 1225-1230. http://dx.doi.org/10.1098/rspb.2008.0022

Wang, L., Chen, L., \& Jacob, T. (2004). Evidence for peripheral plasticity in human odour response. J. Physiol, 554, 236-244. http://dx.doi.org/10.1113/jphysiol.2003.054726

Wedekind, C., \& Penn, D. (2000). MHC genes, body odours, and odour preferences. Nephrol. Dial. Transplant., 15, 1269-1271. http://dx.doi.org/10.1093/ndt/15.9.1269

Wedekind, C., Seebeck, T., Bettens, F., \& Paepke, A. J. (1995). MHC-dependent mate preferences in humans. Proc. Biol. Sci., 260, 245-249. http://dx.doi.org/10.1098/rspb.1995.0087

Weisfeld, G. E., Czilli, T., Phillips, K. A., Gall, J. A., \& Lichtman, C. M. (2003). Possible olfaction-based 
mechanisms in human kin recognition and inbreeding avoidance. J. Exp. Child Psychol., 85, 279-295. http://dx.doi.org/10.1016/S0022-0965(03)00061-4

Yamazaki, K., \& Beauchamp, G. K. (2007a). Genetic basis for MHC-dependent mate choice. Adv. Genet., 59, 129-145. http://dx.doi.org/10.1016/S0065-2660(07)59005-X

Yamazaki, K., Beauchamp, G. K., Curran, M., Bard, J., \& Boyse, E. A. (2000). Parent-progeny recognition as a function of MHC odortype identity. Proc. Natl. Acad. Sci. USA, 97, 10500-10502. http://dx.doi.org/10.1073/pnas.180320997

Yamazaki, K., Beauchamp, G. K., Wysocki, C. J., Bard, J., Thomas, L., \& Boyse, E. A. (1983). Recognition of H-2 types in relation to the blocking of pregnancy in mice. Science, 221, 186-188. http://dx.doi.org/10.1126/science.6857281

Ziegler, A., Santos, P. S., Kellermann, T., \& Uchanska-Ziegler, B. (2010). Self/nonself perception, reproduction and the extended MHC. Self Nonself, 1, 176-191. http://dx.doi.org/10.4161/self.1.3.12736 